\title{
Blickdiagnose
}

\section{Flächenhafte Entzündung im Gesicht}

Eine 35-jährige Frau stellt sich mit einer flächenhaften, ödematösen und geröteten Schwellung im Gesicht vor, die periorbital besonders stark ausgeprägt ist und mit Bläschen einhergeht. Sie fühlt sich krank und berichtet, dass die Entzündung vor wenigen Tagen mit hohem Fieber begonnen hat.

\section{Diskussion}

Die Patientin leidet an einem Gesichtserysipel. Das Erysipel ist eine Infektionskrankheit, die durch $\beta$-hämolysierende Streptokokken der Gruppe A (seltener Streptokokken anderer Gruppen), Staphylococcus aureus und grammnegative Stäbchen verursacht wird. Die Erreger gelangen über Bagatellverletzungen in die Haut, die Entzündung breitet sich dann flächenhaft in Kutis und Subkutis aus. Die Erkrankung beginnt zumeist hochfieberhaft mit einem Spannungsgefühl der Gesichtsweichteile und rasch folgender flächenhafter Rötung und Schwellung. Das Gewebe ist überwärmt, gelegentlich zeigen sich Bläschen. Breitet sich das Gesichtserysipel seitlich von Nase und Lidbereich aus, besteht die Gefahr der endokraniellen Beteiligung über eine hämatogene Ausbreitung der Erreger.

Vorgeschichte, Verlauf und klinisches Befundbild sind zumeist eindeutig. Differenzialdiagnostisch sind Lupus erythe-

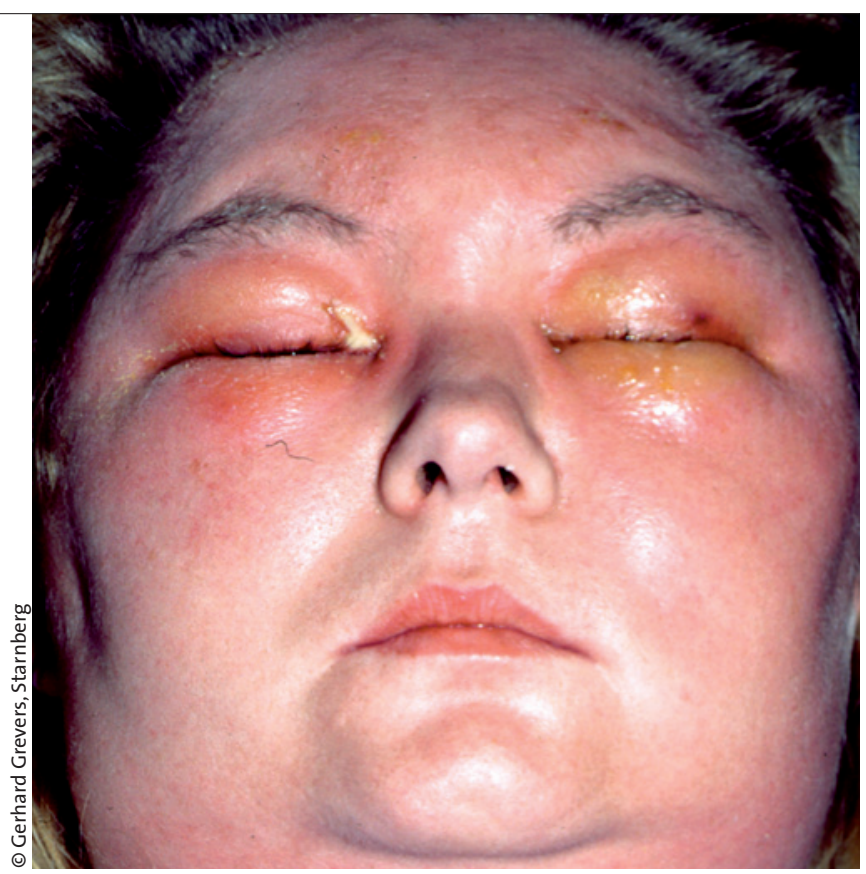

Ausgeprägte ödematöse und gerötete flächenhafte Schwellung der Gesichtsweichteile mit periorbitaler Bläschenbildung

matodes, allergische Kontaktdermatitis, Angioödem sowie die Fasciitis necroticans zu bedenken und auszuschließen.

Therapie der Wahl ist die parenterale Antibiotikabehandlung mit Penicillin; ergänzend können lokal feuchte Umschläge mit Desinfizienzienlösungen angelegt werden.

\section{Literatur beim Verfasser}

\section{Prof. Dr. med. Gerhard Grevers}

Prinzenweg 1

82319 Starnberg

Grevers@gmx.de 